\title{
Autophagy protein NRBF2 has reduced expression in Alzheimer's brains and modulates memory and amyloid-beta homeostasis in mice
}

Véronik Lachance ${ }^{1}$, Qian Wang ${ }^{1,2}$, Eric Sweet ${ }^{1,3,4}$, Insup Choi ${ }^{1}$, Cui-Zan Cai ${ }^{5}$, Xu-Xu Zhuang ${ }^{5}$, Yuanxi Zhang ${ }^{1}$, Jessica Li Jiang ${ }^{1}$, Robert D. Blitzer ${ }^{3}$, Ozlem Bozdagi-Gunal ${ }^{6,7}$, Bin Zhang ${ }^{2}$, Jia-Hong Lu ${ }^{5^{*}}$ and Zhenyu Yue ${ }^{1^{*}}$

\begin{abstract}
Background: Dysfunctional autophagy is implicated in Alzheimer's Disease (AD) pathogenesis. The alterations in the expression of many autophagy related genes (ATGs) have been reported in AD brains; however, the disparity of the changes confounds the role of autophagy in $A D$.

Methods: To further understand the autophagy alteration in AD brains, we analyzed transcriptomic (RNAseq) datasets of several brain regions (BA10, BA22, BA36 and BA44 in 223 patients compared to 59 healthy controls) and measured the expression of 130 ATGs. We used autophagy-deficient mouse models to assess the impact of the identified ATGs depletion on memory, autophagic activity and amyloid- $\beta(A \beta)$ production.

Results: We observed significant downregulation of multiple components of two autophagy kinase complexes BECN1-PIK3C3 and ULK1/2-FIP200 specifically in the parahippocampal gyrus (BA36). Most importantly, we demonstrated that deletion of NRBF2, a component of the BECN1-PIK3C3 complex, which also associates with ULK1/2-FIP200 complex, impairs memory in mice, alters long-term potentiation (LTP), reduces autophagy in mouse hippocampus, and promotes A 3 accumulation. Furthermore, AAV-mediated NRBF2 overexpression in the hippocampus not only rescues the impaired autophagy and memory deficits in NRBF2-depleted mice, but also reduces $\beta$-amyloid levels and improves memory in an AD mouse model.

Conclusions: Our data not only implicates NRBF2 deficiency as a risk factor for cognitive impairment associated with AD, but also support the idea of NRBF2 as a potential therapeutic target for AD.
\end{abstract}

\section{Background}

Alzheimer's disease (AD) is the leading cause of dementia affecting our elders and the seventh cause of death worldwide. While genetic variants contribute to a subset of $\mathrm{AD}$ cases, aging persist to be the primary risk factor for $\mathrm{AD}$. In addition, the pathological hallmarks of $A D$ are the excessive $\beta$-amyloid deposits $(A \beta)$ and intraneuronal neurofibrillary tangles containing hyperphosphorylated-tau (pTau) [1-3]. The aberrant

\footnotetext{
* Correspondence: jiahonglu@um.edu.mo; zhenyu.yue@mssm.edu

${ }^{5}$ State Key Laboratory of Quality Research in Chinese Medicine, Institute of Chinese Medical Sciences, University of Macau, Taipa, Macau SAR, China 'Department of Neurology, The Friedman Brain Institute, Icahn School of Medicine at Mount Sinai, New York, NY 10029, USA

Full list of author information is available at the end of the article
}

accumulation of $A \beta$ and $p$ Tau suggests a failure of protein handling system during the course of the disease. In fact, loss of the proteostasis network - including the autophagy pathway - is implicated in the pathogenesis of $\mathrm{AD}[4-8]$.

Over the past decades, many studies have documented the dysregulation of autophagy in $\mathrm{AD}$ postmortem brains and experimental models. Early ultrastructural analysis of $\mathrm{AD}$ brains showed accumulation of autophagic vacuoles (AVs) in dystrophic neurites [9] and examination of autophagy pathway showed upregulation of mTOR activity, a negative regulator of autophagy signaling [10], and reduced expression of Beclin 1, a core component of class III PI3-kinase (PIK3C3) that controls

(C) The Author(s). 2019 Open Access This article is distributed under the terms of the Creative Commons Attribution 4.0 International License (http://creativecommons.org/licenses/by/4.0/), which permits unrestricted use, distribution, and 
autophagy initiation [11], therefore suggesting that autophagy is impaired in AD. However, a genome-wide analysis indicated a transcriptional upregulation of autophagy in entorhinal cortex of AD patients [12], and others reported hyperactivation of AMPK, a positive autophagy signaling kinase, thus supporting an enhanced autophagic activity in AD [13-15]. A recent finding showed that hippocampal neurons isolated from $\mathrm{AD}$ subjects contained greater expression of genes or proteins related to autophagosomes and lysosomes biogenesis. However, the same study suggests an impediment of autophagy flux despite the enhanced autophagy biogenesis [16]. Thus, the available evidence for autophagy alteration in $\mathrm{AD}$ appears conflicting, obscuring the role of autophagy in the disease's onset and progression. It is conceivable that multiple factors may contribute to the discrepancies in these results, such as the small sample size, the disease stages, the distinct brain regions and the ATGs examined. Hence, studies with increased sample size and improved approaches are necessary to comprehend the precise function of autophagy in AD. Herein, we examined the expression of over 100 autophagy related (ATG) genes in multiple brain regions from more than 200 AD postmortem brains. Our analysis revealed significant downregulation of genes encoding autophagy kinase complexes in the parahippocampal gyrus and hippocampus. Our data suggest that loss of NRBF2 functions in the hippocampus impairs memory in mice and may contribute to the cognitive impairment associated with AD. Our study also supports NRBF2 as a potential therapeutic target.

\section{Methods}

\section{Bioinformatics analysis}

A list of 130 core ATGs was manually curated based on literature reviews $[17,18]$ and public database (www.tanpaku. org/autophagy/) [19]. Expression of these genes was examined at the mRNA level in multiple brain regions of healthy control and AD patient samples from the Mount Sinai Brain Bank https://www.synapse.org/\#!Synapse:syn3157743) [20]. Differential gene analysis was performed using Bioconductor R Limma Package [21] with Benjamini-Hochberg correction for multiple testing. Spearman correlation analysis was performed to examine the relationship between ATG expression and CDR score. Adjusted $p$ value $<0.05$ was considered statistically significant.

\section{Animals}

Subjects were housed in groups of two to five. Food and water were supplied ad libitum in an animal facility with a regular $12 \mathrm{~h} \mathrm{light/dark} \mathrm{cycle} \mathrm{(light} \mathrm{on} \mathrm{at} \mathrm{7:00} \mathrm{A.M.).}$ Tails were cut and ears were notched when pups were 7-14 days for genotyping and identification purposes respectively. NRBF2-KO mouse genotyping was performed as mentioned in [22] and the standard protocol of Jackson Laboratory was used for the 5XFAD mouse genotyping (stock number 008730). Mice were weaned at 21 days. Unless mentioned, mice used in this study were from three different cohorts, aged around 3-4 months. For all test conditions, the male:female ratio was $\sim 1: 1$ and compare to WT littermate controls.

\section{Reagents}

NuPAGE ${ }^{\circledast}$ MOPS SDS Running Buffer (20X), (\#NP0 001-02), NuPAGE ${ }^{\odot}$ MES SDS Running Buffer (20X), (\#NP0002-02), NuPAGE ${ }^{\text {тм }}$ 4-12\% Bis-Tris Protein Gels, 1.0 mmX15well, (\#NP0323BOX), NuPAGE ${ }^{\mathrm{mm}} 4-12 \%$ BisTris Protein Gels, $1.0 \mathrm{mmX26well,} \mathrm{( \# WG1403BOX)} \mathrm{and}$ PierceTM BCA Protein Assay Kit (\#23225) and ProLong Diamond antifade mountant with or without DAPI (\#P36962 or \#P36961) were from Thermo Scientific. Western Lightning Plus ECL (\#NEL105001EA) was from PerkinElmer. Immobilon ${ }^{\oplus}$ FL Transfer membrane 0.45 um, Polyvinylidene Difluoride (PVDF) membrane (\#ISE Q00010) was from Merck Millipore. HyBlot CL films (\#E3012) were from Denville Scientific, Inc. Non-fat dry milk (\#M0841) was from Lab Scientific. Protease and Phosphatase inhibitors tablets (\#88669) were from Thermo Scientific. Dynabeads Protein G was from Novex (Life Technologies, \#10004D). Ponceau S Solution (\#P7170) was from Sigma-Aldrich. OCT compound (\#23-730-571) and microscope slides (\# 12-550-15) were from Fisher Scientific. Liquid blocker pap pen (\#71310) was from Electron Microscopy Sciences (EMS).

\section{Antibodies}

\section{Immunoblotting}

AMPK $\alpha$ (D5A2) Rabbit mAb (\#5831, 1:1000), phosphoAMPK $\alpha$ (Thr172) (40H9) Rabbit mAb (\#2535, 1:500), Raptor (24C12) Rabbit mAb (\#2280, 1:500), phospho-Raptor (Ser792) Rabbit polyclonal antibody (pAb) (\#2083, 1:500), mTOR (7C10) Rabbit mAb (\#2983, 1:500), phosphomTOR (Ser2481) Rabbit pAb (\#2974, 1:500), 4E-BP1 (\#9452, 1:500), phospho-4E-BP1 (Thr37/46) (236B4) Rabbit mAb (\#2855, 1:1000), ULK1 (D8H5) Rabbit mAb (\#8054, 1: 500), FIP200 (D10D11) Rabbit mAb (\#12436, 1:250), LC3B Rabbit pAb (\#2775, 1:1000) and Rabbit (DA1E) mAb IgG $\mathrm{XP}^{\oplus}$ Isotype Control (\#3900) were from Cell Signaling Technology. Goat anti-Rabbit IgG-HRP pAb (sc-2004, 1: 1000) were from Santa Cruz Biotechnology, Inc. NRBF2 Rabbit pAb (A301-851A) was from Bethyl Laboratories, Inc. P62 Guinea pig pAb (\#GP62-C, 1:4000) was from PROGEN. P62 Guinea pig pAb (PM066, 1:4000) was from Medical and Biological Laboratories Co., LTD. (MBL). Goat anti-Mouse IgG-HRP (\#A28177, 1:1000), goat anti-Guinea Pig IgG-HRP (\#A18775, 1:1000) antibodies were from Thermo Scientific. PSD95 (6G6-1C9) mAb (\#MA1-045, 1: 
1000) was from Thermo Scientific. VAMP2 Rabbit pAb (\#104202, 1:5000) was from Synaptic Systems.

\section{Immunohistochemistry}

Phophos- AMPKa (Thr172) Rabbit pAb (\#AP0432, 1:200

IHC) was from ABclonal Technology. $\beta$-Amyloid (D54D2) Rabbit monoclonal antibody (mAb) (\#8243, 1:500) and cleaved Caspase-3 (Asp175) Rabbit pAb (\#9661, 1:100) were from Cell Signaling Technology. Goat anti-Rabbit IgG-Alx647 (\#A21246, 1:500) antibody was from Thermo Scientific.

\section{Perfusion and Cryo-sectioning}

Mice were transcardially perfused with $25-30 \mathrm{ml}(6-7$ $\mathrm{ml} / \mathrm{min}$.) of ice-cold PBS $1 \mathrm{X}$ to remove excess blood, then perfused with $25-30 \mathrm{ml}$ of ice-cold $4 \%$ paraformaldehyde. After perfusion, the brain was removed from the skull and fixed overnight at $4{ }^{\circ} \mathrm{C}$ in $15 \mathrm{ml}$ falcon tube filled with $4 \%$ PFA. The next morning, the brain were washed $3 \mathrm{x}$ with $15 \mathrm{ml}$ of ice-cold PBS $1 \mathrm{X}$ and incubate with $15 \mathrm{ml}$ of $30 \%$ sucrose solution for at least $24 \mathrm{~h}$ or up until the brain has sunk at the bottom of the tube. Left and right sagittal hemisphere were divided, embedded in OCT compound, gradually froze in liquid nitrogen, and stored at $-80^{\circ} \mathrm{C}$. Cryo-sectioning was performed using Leica CM3050 S cryostat. $40 \mu \mathrm{m}$ sagittal sections were conserved at $-20^{\circ} \mathrm{C}$ in anti-freezing medium $(25 \%$ glycerol, $30 \%$ ethylene glycol, $50 \mathrm{mM}$ phosphate buffer $\mathrm{pH}$ 7.4).

\section{Heat-induced epitope retrieval}

The protocol used is based on the following reference [23]. Briefly, sections were wash $3 \times 10 \mathrm{~min}$. With $500 \mu \mathrm{l}$ PBS $1 \mathrm{X}$ at RT on microscope slides and allowed to dry for 20-30 min. in the dark. Next, we incubate the slides in pre-warmed citrate buffer $(10 \mathrm{mM}$ Sodium Citrate dihydrate $\mathrm{pH} 6.0,0.05 \%$ Tween 20) in a water bath heated at $65^{\circ} \mathrm{C}$ for $45 \mathrm{~min}$. After incubation, slides were washed $3 \times 10 \mathrm{~min}$. at RT with PBS $1 \mathrm{X}$ while shaking. A final wash was executed for $10 \mathrm{~min}$. at room temperature (RT) with PBS $1 \mathrm{X}$ containing $0.1 \%$ Triton-X-100.

\section{Immunofluorescence and confocal imaging}

Brain sections were encircled with liquid blocker pap pen and blocked with $150 \mu \mathrm{l} /$ section PBS containing 5\% goat serum and $0.1 \%$ Triton X-100 for $1 \mathrm{~h}$ at RT. Sections were incubated in a humid chamber with $100 \mu \mathrm{l}$ of primary antibody diluted in blocking buffer overnight at $4{ }^{\circ} \mathrm{C}$. After washing $3 \times 10 \mathrm{~min}$. With $150 \mu \mathrm{l}$ PBS, sections were incubated with $100 \mu$ l Alexa-conjugated secondary antibody for $1 \mathrm{~h}$ at RT. After 4 washes with PBS, sections were mounted with ProLong Diamond antifade reagent. Sections were examined under Carl Zeiss upright confocal microscope (LSM780 system). Images were taken sequentially with $40 \mathrm{X}$ oil immersion objective lens at
RT. Single or tile scan acquisitions were performed by Zen2012 software.

\section{Confocal image analysis}

Basic Intensity Quantification was performed with Image J. RGB pictures were converted into single 16-bit grayscale images. A duplicate of the grayscale picture was generated and further processed into a binary picture. The background was subtracted with the rolling ball (radius of 50.0 pixels) tool with light background and sliding paraboloid options selected. The threshold was finally adjusted to highlight all the structures having signal. Next, we calibrated the scale, set the measurements, and redirect it to the original grayscale image. The particles were analyzed and stated as mean gray intensity over the total area $\left(\mu \mathrm{m}^{2}\right)$. We finally normalized these data to the WT mean values and reported the fold change.

\section{Tissue homogenization}

Once the tissue harvested and flash frozen, $400 \mu \mathrm{l}$ of homogenization buffer $(0.32 \mathrm{M}$ sucrose, $1 \mathrm{mM} \mathrm{NaHCO}$, $20 \mathrm{mM}$ HEPES, $0.25 \mathrm{mM} \mathrm{CaCl}_{2}, 1 \mathrm{mM} \mathrm{MgCl}_{2}$ and protease/phosphatase inhibitors) were added to $0.1 \mathrm{~g}$ of tissue and homogenized with blue pestle and cordless pestle motor in 1.5 or $2.0 \mathrm{ml}$ Eppendorf tube. Using insulin syringe, 20 up and down were performed to disrupt the tissue. The homogenates were incubated for $30 \mathrm{~min}$. at $4^{\circ} \mathrm{C}$ using end over end mixing. Then the samples were centrifuged at $1500 \times \mathrm{g}$ for $10 \mathrm{~min}$. at $4{ }^{\circ} \mathrm{C}$, the supernatant harvested, and the pellet discarded. Samples were diluted 1:10 and protein concentration was measured.

\section{Immunoprecipitation}

Immunoprecipitations (IPs) were performed using $150 \mu \mathrm{g}$ of proteins extracted from hippocampal homogenates diluted in $300 \mu \mathrm{l}$ of homogenization buffer. Anti-ULK1 antibody $(1: 150, \mathrm{v} / \mathrm{v})$ or isotype control (same concentration than ULK1 $\mathrm{Ab}$ ) were added to each tube and incubated overnight at $4{ }^{\circ} \mathrm{C}$ with end over end agitation. The next morning, $30 \mu \mathrm{L}$ of Dynabeads Protein G was added, followed by an $1 \mathrm{~h}$. incubation at $4{ }^{\circ} \mathrm{C}$. Samples were then centrifuge $1 \mathrm{~min}$ at $4000 \mathrm{RPM}$ in a microcentrifuge and washed three times with $1 \mathrm{~mL}$ of homogenization buffer, immunoprecipitated proteins were eluted by addition of $30 \mu \mathrm{L}$ of $4 \mathrm{X}$ SDS sample buffer, followed by a $10 \mathrm{~min}$. Incubation at $95^{\circ} \mathrm{C}$. Initial lysates and immunoprecipitated proteins were analyzed by SDS-PAGE and immunoblotting with specific antibodies.

\section{Immunoblotting}

All biological samples have been analyzed at least in duplicate in two independent experiments. Samples were diluted to $1 \mathrm{mg} / \mathrm{ml}$ with buffer and SB4X denaturation 
buffer (200 mM 4X Tris-HCl/SDS ph 6.8, 8\% SDS, 400 mM DTT, 40\% glycerol (v/v) 0.4\% Bromophenol Blue) diluted to 1X. Samples were denatured at $95^{\circ} \mathrm{C}$ for 10 min and spin at RT for $30 \mathrm{~s}$ at $14000 \mathrm{rpm}$. $10 \mu \mathrm{g}$ of protein samples were separated on 4-12\% Bis-Tris NuPAGE gels for $70-80 \mathrm{~min}$. at $150 \mathrm{~V}$ at room temperature (RT) using 1X MOPS or 1X MES buffer (Invitrogen). The proteins were transferred to a PVDF membrane for $1 \mathrm{~h}$ at $100 \mathrm{~V}$ at $4{ }^{\circ} \mathrm{C}$. The membranes were dried and stained for $10 \mathrm{~min}$. With Ponceau S. Excess stain was removed for $2 \mathrm{~min}$. With Milli-Q water. The membranes were scanned, cut and block in TBS $1 \mathrm{X}$ containing $0.1 \%$ Tween 20 (TBST) and $5 \%$ non-fat dry milk for $1 \mathrm{~h}$ at RT. Primary antibodies were applied, and membranes were incubated overnight at $4{ }^{\circ} \mathrm{C}$. The membranes were washed $3 \times 8 \mathrm{~min}$. With TBST. Secondary antibodies were applied, and membranes were incubated for $1 \mathrm{~h}$ at RT. The membranes were washed $3 \times$ $8 \mathrm{~min}$. With TBST and twice with TBS $1 \mathrm{X}$. The proteins were visualized using ECL detection kit.

\section{Immunoblot membrane stripping}

After phospho-antibodies detection, membranes were washed once during $10 \mathrm{~min}$. in distilled water to remove ECL. Membranes were incubated $3 \times 10 \mathrm{~min}$. in $\mathrm{NaOH}$ $(0.2 \mathrm{M})$ solution to strip off the antibodies. Membranes were finally incubated in TBST buffer for $10 \mathrm{~min}$. and the blotting procedure was started over.

\section{Densitometry analysis}

Western blot quantification was performed based on the recommendations of Gassmann et al. [24]. All quantified immunoblots were revealed using the same type of films and carefully exposed to avoid saturation. Films were scanned using an Epson Perfection v500 or v800 Photo scanner. Acquisition was performed at $600 \mathrm{dpi}$ in 16-bits grayscale with auto-exposure and colour-correction options turned off. Images were analyzed using the ImageJ software. Lanes were selected and plotted using the 'Gel analyzer' functions. Peaks on the plots were individually closed to the background level of each lane using the Straight line' tool and the enclosed area was measured using the 'Wand' tool.

\section{Stereotaxic surgery}

Stereotaxic delivery of recombinant adeno-associated virus, serotype 9 (AAV) for expression of a mCherry or NRBF2-mCherry fusion protein under control of the CMV promoter was done as follows: mice were anesthetized with $2 \%$ isoflurane and $1 \mu \mathrm{l}$ of virus for each hemisphere $\left(\sim 5.8 \times 10^{10}\right.$ viral genomic copies) was injected at a rate of $0.2 \mu \mathrm{l} / \mathrm{min}$ using a Hamilton syringe, a micro pump, and stereotaxic instrument (Stoelting). Syringe remained in place for an additional $2 \mathrm{~min}$. After completion of the injection. Coordinates for injection were as follows: $-2.0 \mathrm{~mm}$ anterior/posterior, $\pm 1.5 \mathrm{~mm}$ medial/lateral, and $-1.75 \mathrm{~mm}$ dorsal/ventral. Viruses were produced and purified by Vigene Biosciences Inc. (Rockville, MD, USA).

\section{Mouse $A \beta_{42}$ ELISA}

$A \beta_{42}$ level was quantify from hippocampal extracts. Fractions were analyzed in duplicate. Same protein amount was loaded into each well, and the plate was incubated overnight at $4{ }^{\circ} \mathrm{C}$ with gentle agitation. ELISA was performed according to the manufacturer's instructions (\#KMB3441, Thermo Scientific).

\section{Behavior studies \\ Object Location Task (OLT) [25]}

On habituation day (day 1), mice were individually placed into an open-field box $(40 \times 40 \mathrm{~cm})$ surrounded by $40 \mathrm{~cm}$ high walls made of transparent plastic and allowed to freely explore the arena for $5 \mathrm{~min}$ in an infrared-lit room. On training day (day 2), mice were placed into the previously explored box now containing two similar objects and allowed to explore for $10 \mathrm{~min}$. On testing day (day 3), one object was moved forward, and the mice were placed back into the arena and allowed to explore for $10 \mathrm{~min}$. Videos were recorded by the EthoVision video tracking system (Noldus, Wageningen, The Netherlands) and were manually scored. Object explorations were counted once the following criteria have been met: the snout of the mouse is oriented toward and close to the object and the animal's body is beyond the object (no climbing). To assess object bias we evaluate the time spent sniffing each object on day 2 relative to the total time spent exploring (Time spent sniffing object 1 / Total time spent sniffing object 1 and $2 \times 100 \%)$. Mice exhibiting an object bias score below 0.2 or above 0.8 were excluded. Discrimination ratio was calculated as follows: time spent sniffing the object divided by the total time spent sniffing both objects, Score equivalent to 0.5 indicates equal time spent exploring the displaced and familiar objects.

\section{Contextual fear conditioning (CFC)}

CFC experiments were conducted in sound attenuating chambers with automated stimulus delivery software (Med Associates, St. Albans, VT, USA). On training day, mice were exposed to a $218 \mathrm{~s}$ period of acclimation to the conditioning arena (context $\mathrm{A}$ ) followed by three consecutive foot shocks $(0.5 \mathrm{~mA}, 2 \mathrm{~s}, 100 \mathrm{~s}$ interval between shocks) and a final $30 \mathrm{~s}$ resting period. On testing day, mice were re-exposed to context A for $3 \mathrm{~min}$. One hour after re-exposure to context A, mice were placed in a modified arena (context B) and allowed to explore for $3 \mathrm{~min}$. Percentage time freezing was quantified by 
automated motion-sensitive software (Video Freeze; Med Associates).

\section{Radial-arm maze (RAM) [26]}

The maze consisted of eight arms $(7.5 \times 35 \mathrm{~cm}, 17.5 \mathrm{~cm}$ high walls) assembled radially around a circular starting platform. Mice were placed onto the starting platform and were free to enter the arms. Mice were tested until all eight arms were visited once. Each repeated entry in arm was counted as an error. Mice were trained on day 1 and tested on day 2 .

\section{Spontaneous Alternation Task (SAT) [25]}

The Y-Maze (Maze Engineers) consisted of three gray acrylic closed arms measuring $35 \mathrm{~cm} \mathrm{~L} \times 5 \mathrm{~cm} \mathrm{~W} \times 20 \mathrm{~cm}$ $\mathrm{H}$. Mice were placed in the center of the maze and were free to explore for $10 \mathrm{~min}$. The number of alternation and the number of entries were recorded and scored by the EthoVision video tracking system (Noldus, Wageningen, The Netherlands). Percentage of alternation was calculated as the number of alternation/ (total number of entries - 2) $\times 100$. Total number of entries was reported to control any potential hyperactivity.

\section{Hippocampal slice preparation and field electrophysiology}

Hippocampal slices $(350-400 \mu \mathrm{m})$ were prepared from NRBF2-deficient mice and wild type littermates. Slices were perfused with Ringer's solution containing (in $\mathrm{mM}$ ): $\mathrm{NaCl}$, 125.0; KCl, 2.5; $\mathrm{MgSO}_{4}, 1.3 ; \mathrm{NaH}_{2} \mathrm{PO}_{4}, 1.0 ; \mathrm{NaHCO}_{3}, 26.2$; $\mathrm{CaCl}_{2}$, 2.5; glucose, 11.0, and bubbled with $95 \% \mathrm{O} 2 / 5 \% \mathrm{CO} 2$, at $32{ }^{\circ} \mathrm{C}$ during extracellular recordings. Slices were maintained for $1-2 \mathrm{~h}$ prior to establishment of a baseline of field excitatory postsynaptic potentials (fEPSPs) recorded from stratum radiatum in area CA1, evoked by stimulation of the Schaffer collateral-commissural afferents $(100 \mu$ s pulses every $30 \mathrm{~s}$ ) with bipolar tungsten electrodes placed into area CA3 [27]. The EPSP initial slope $(\mathrm{mV} / \mathrm{ms})$ was determined from the average waveform of four consecutive responses. After determining the input/output relationship, long-term potentiation (LTP) was induced by a high-frequency stimulus (four trains of $100 \mathrm{~Hz}, 1 \mathrm{~s}$ stimulation separated by $5 \mathrm{~min}$ ) with a success rate $>90 \%$. Field EPSP initial slopes from averaged traces after LTP induction were normalized to baseline.

\section{Statistical analysis}

Statistical analyses were performed using GraphPad Prism version 8.1 for Windows (GraphPad Software) using the unpaired one- or two-tailed Student's t test and Regular or Row-Matched Two-way ANOVA test followed by Bonferroni's multiple comparisons test. Data were considered significant when $P$ values were $<0.05$ $\left({ }^{*}\right),<0.01\left(^{* * *}\right)$ or $\left.<0.001{ }^{* * * *}\right)$.

\section{Results}

Analysis of AD brains reveals autophagy alterations and reduced NRBF2 expression in the parahippocampal gyrus and hippocampus

We performed differentially expressed gene (DEG) analysis and examined the fold change of $~ 130$ ATGs in multiple brain areas by analyzing transcriptomic datasets collected from late-onset AD (LOAD) postmortem brains (Mount Sinai Brain Bank, MSBB) [20] and laser-capture microdissected (LCM) neuron-enriched extracts from AD brains (GSE5281) [28] (Table 1 and Additional file 1: Table S1), thus greatly enhancing the statistical power of this study compared to others $[11,12,16]$. The DEG analysis of the MSBB cohort showed only one out of 4 brain regions, i.e. parahippocampal gyrus (PHG), with significant changes in more than 50 ATGs (Fig. 1a and Additional file 2: Figure S1A-B). The upregulated genes are functionally clustered as upstream autophagy regulators, while the downregulated genes are enriched for core autophagy machinery including autophagosome biogenesis, such as GABARAPL1, ATG5, NRBF2, BECN1-PIK $3 C 3$ complex, ULK1/2-ATG13-RB1CC1/FIP200 complex and a few signaling molecules of autophagy. Of note, downregulation of $N R B F 2$ and a few other proteins are

Table 1 Description of the dataset used in this study

\begin{tabular}{|c|c|c|c|c|}
\hline Sample & Brain Bank (Template) & Brain Region & Control & $A D$ \\
\hline \multirow[t]{4}{*}{ Tissue } & MSBB (RNAseq) & BA10-Anterior prefrontal cortex & 59 & 223 \\
\hline & & BA22-Superior Temporal Gyrus & & \\
\hline & & BA36-Parahippocampal Gyrus & & \\
\hline & & BA44-Inferior Frontal Gyrus & & \\
\hline \multirow[t]{6}{*}{ LCMed Neurons } & GSE5281 (Array) & Entorhinal Cortex & 13 & 10 \\
\hline & & Hippocampus & 13 & 10 \\
\hline & & Medial Temproral Gyrus & 12 & 16 \\
\hline & & Posterior Cingulate & 13 & 9 \\
\hline & & Superior Frontal Gyrus & 11 & 23 \\
\hline & & Visual Cortex & 12 & 19 \\
\hline
\end{tabular}



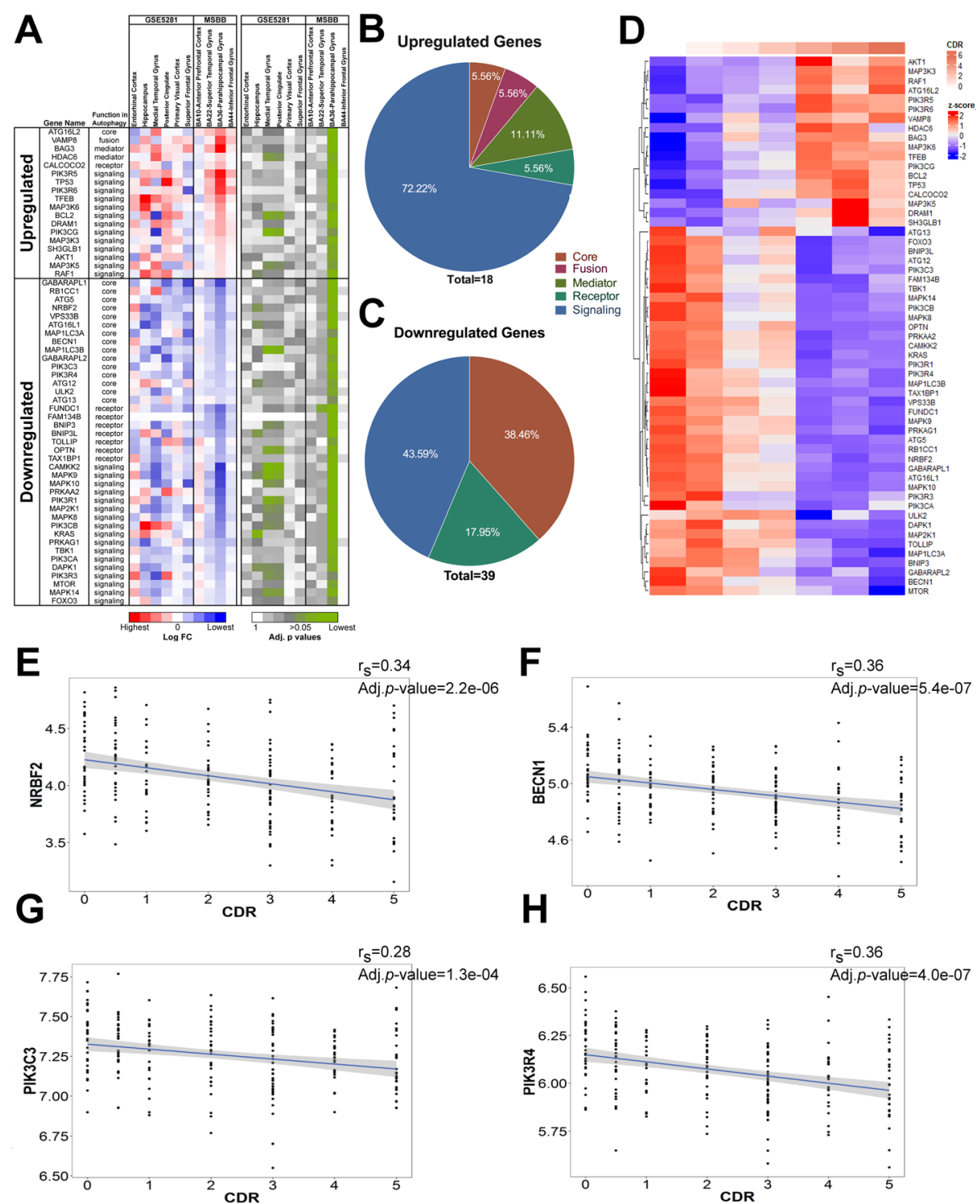

Fig. 1 ATGs expression is altered in PHG and hippocampus of AD postmortem brains. a Heatmap of the Log FC and adjusted $p$ values of the significantly up- and down-regulated ATG expressions found in PHG (BA36) and their counterpart expression in GSE5281 and other MSBB datasets. b-c Pie charts representing the autophagy gene functions associated to the upregulated or downregulated ATGs identified in (a). d Heatmap representing the mean z-score expression of each significant ATGs at different CDR stages within the PHG (MSBB-BA36). e-h NRBF2, $B E C N 1$, PIK3C3 and PIK3R4 gene expressions are progressively reduced in the PHG as a function of CDR score

also statistically significant in hippocampal neurons of AD brains, as well as in medial temporal gyrus and posterior cingulate, based on the GSE5281 data (Fig. 1a-c). Expression pattern of these 50 ATGs correlates either positively or negatively with the clinical dementia rating (CDR) score (Fig. 1d). Interestingly, NRBF2, BECN1, PIK3C3 and PIK3R4, which encode different protein subunits of the same lipid kinase complex, are all significantly reduced, and their expression inversely correlate with the CDR score in the PHG (Fig. 1e-h). Given the functional relationship of these proteins in the PIK3C3 kinase complex, the above data suggest that a progressive decline of the
NRBF2-associated BECN1-PIK3C3 kinase activity might occur during the course of AD in the PHG and hippocampus. In fact, we recently reported that NRBF2 and Beclin 1 expression were also reduced in hippocampus of 5XFAD mouse model [29]. Thus, we decided to further investigate the role of NRBF2 in AD related symptoms.

\section{NRBF2 depletion reduces autophagy, causes memory deficits, and impairs long-term potentiation}

Previous studies have shown the scaffolding role of NRBF2 in BECN1-PIK3C3 and ULK1 complexes assembly in cell lines [22, 30-34]. We have shown that NRBF2 deletion 
reduces BECN1-PIK3C3-lipid kinase activity in the brain [22] and further demonstrated that ULK1-FIP200 complex stability is also compromised (Additional file 2: Figure S2AD). Therefore, we evaluated the autophagy flux in different brain regions and $\mathrm{AD}$-related phenotypes in these $\mathrm{KO}$ mice. First, we noticed a higher expression of NRBF2 in the hippocampus and striatum compared to other brain regions of wild-type (WT) mice. Upon NRBF2 deletion, autophagy markers, p62 and LC3-II, accumulated most significantly in the hippocampus (Additional file 2: Figure S3A-D, F) [35]. We observed little change in p62 and LC3A/B mRNA levels in NRBF2-KO hippocampus (Additional file 2: Figure S3E), suggesting that p62 or $\mathrm{LC} 3 \mathrm{~A} / \mathrm{B}$ protein increase is caused by autophagy impairment rather than enhancement of their gene expression. We next performed multiple behavioral tasks to test hippocampal-associated functions. Using open field (OF), light-dark (LD) box and elevated-plus maze (EPM) tasks, we observed that anxiety-related behavior was unchanged in young NRBF2-KO animals (Additional file 2: Figure S4A-C), suggesting that ventral hippocampal functions are unaffected in these mice [36]. Second, we performed an object-location task (OLT) to specifically assess spatial memory, known to rely on proper dorsal hippocampus function [37]. After habituation and training, we found that NRBF2-KO mice performed poorly in discriminating the new location of a familiar object, thus suggesting spatial memory deficits in the mutant mice (Fig. 2a). Third, we performed contextual fear conditioning (CFC) test. On the testing day, we observed that the freezing behavior of NRBF2-KO mice in the training-context $\mathrm{A}$ is reduced when compared to the WT littermates, while no significant change in observed in the context $\mathrm{B}$, thus supporting that loss of NRBF2 causes memory deficits (Fig. 2b). Fourth, we performed a radialarm maze (RAM) test. NRBF2-KO mice showed an

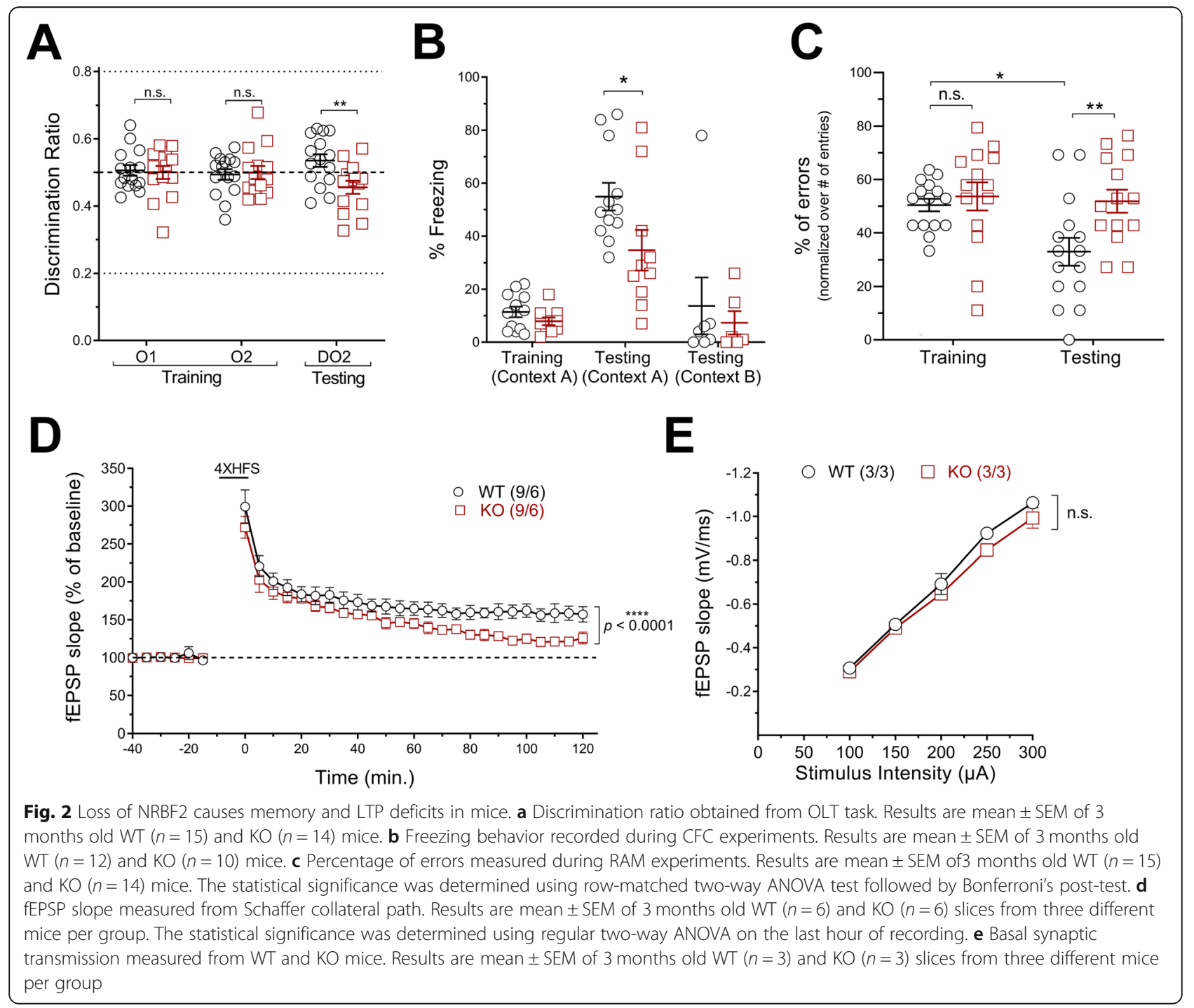


impairment in remembering previously visited arm, as revealed with an increase percentage of errors made on the testing day when compared to the littermate controls (Fig. 2c). We also observed that loss of NRBF2 expression in 5XFAD mice enhances their memory deficits using OL, CFC and RAM behavioral task (Additional file 2: Figure S5A-C).

To further understand the basis of the memory deficits in NRBF2-KO mice, we examine long-term potentiation (LTP), a well-known cellular mechanism linked to learning and memory. Results of the field recordings from the Schaffer collateral pathway showed a reduced maintenance of LTP in NRBF2-KO animals when compared to WT (Fig. 2d), while no change in basal synaptic transmission (Fig. 2e) or expression of pre- and post-synaptic markers (Additional file 2: Figure S6A-C) were observed. Given that AMPK signaling modulates autophagy [38], memory and LTP processes [14, 39, 40], we decided to examine the phosphorylation of AMPK-Thr172 as well as the phosphorylation of Raptor-Ser792 - an AMPK substrate [41] - to understand further the molecular changes occurring in NRBF2-KO hippocampus that could relate to LTP deficit. Western blot analysis showed higher phosphorylation levels of AMPK-Thr172 and Raptor-Ser792 in NRBF2-KO animals, whereas no change of their total protein levels was detected (Additional file 2: Figure S7A-C). We also performed immunofluorescence imaging experiments and showed that CA1 and CA3 pyramidal neurons of NRBF2-KO mice had enhanced phospho-AMPK-T172 signal, thus validating the hyperactivation of AMPK in NRBF2-KO hippocampus (Additional file 2: Figure S7D-E). While increased phosphorylation of Raptor-Ser792 is known to inhibit mTOR kinase function, we examined mTOR catalytic activity through assessment of its autophosphorylation site, i.e. Ser2481, [42] and phosphorylation of 4E-BP1-Thr37/46 [43], a known mTOR substrate, while both are crucial for LTP and memory consolidation [4446]. Immunoblot analysis demonstrated that phosphorylation of mTOR-Ser2481 and 4E-BP1-Thr37/46 were decreased in hippocampal extracts of NRBF2-KO mice when compared to the littermate controls, while no change in these proteins basal expression was observed (Additional file 2: Figure S7F-H). Together, these data suggest that hyperactivation of AMPK and reduced mTOR activity could be related to LTP and memory deficits in NRBF2-KO mice.

\section{Loss of NRBF2 promotes accumulation of APP C-terminal fragments and $A \beta$ in mouse hippocampus}

We next evaluated the $A \beta$ level in the hippocampus of aged NRBF2-KO mice. We detected an accumulation of p62 and APP Carboxyl-terminal Fragments (APP-CTFs) in late adult hippocampus of $N R B F 2-\mathrm{KO}$ mice while observing no significant change in full-length APP (FLAPP) when compared to control (Fig. 3a-e). Our study revealed an increase of $A \beta_{1-42}$ levels in aged KO hippocampal tissue (Fig. 3f). To verify that NRBF2 deletion
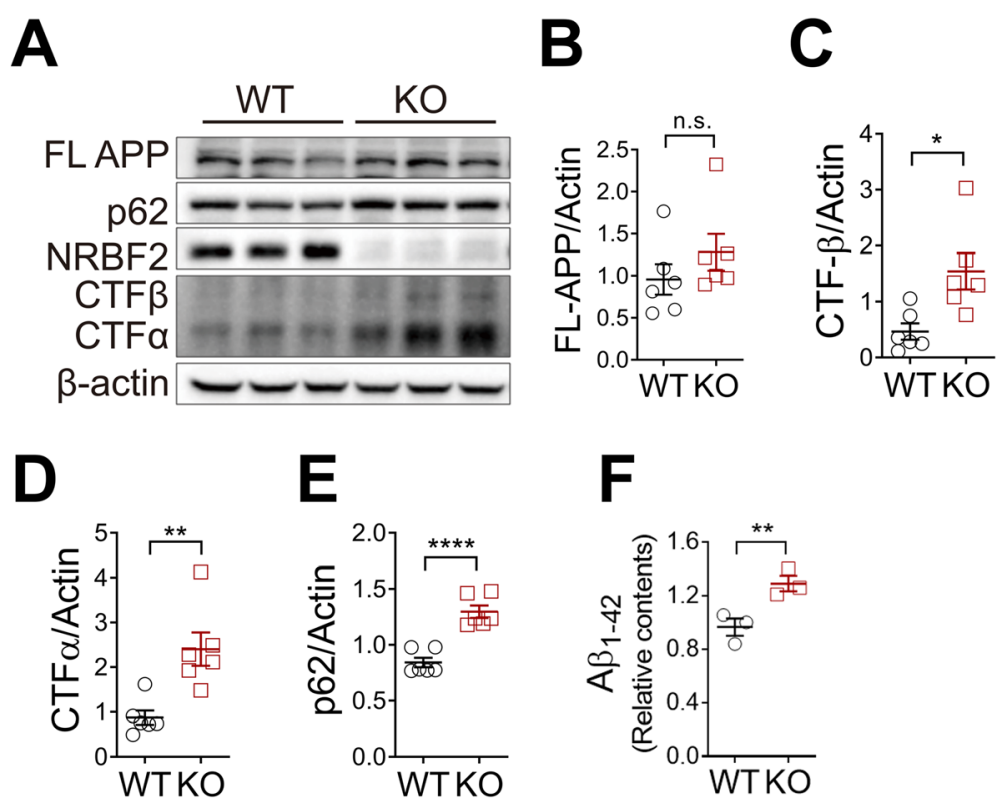

Fig. 3 Deletion of NRBF2 enhances accumulation of APP-CTFs and $A \beta_{42}$ in mouse hippocampus. a Expression of FL-APP, APP-CTFs in the hippocampus of 20-months-old WT $(n=6)$ and NRBF2-KO $(n=6)$ mice. The blots shown are representative of two separate experiments $(\mathbf{b}$-e) Quantification of (a). The statistical significance was determined using two-tailed unpaired Student's t-test. $\mathbf{f}$ ELISA analysis results of A $\beta_{1-42}$ levels in hippocampus of 20- month-old WT $(n=3)$ and NRBF2-KO $(n=3)$ mice. The statistical significance was determined using two-tailed unpaired Student's t-test. ${ }^{*} p<0.05,{ }^{* *} p<0.01,{ }^{* * *} p<0.0001$ 
also promotes the buildup of human insoluble $A \beta_{42}$, we crossed NRBF2-KO mice with 5XFAD mouse model a well characterized AD model known to overproduce $\mathrm{A} \beta_{42}$ [47] - and found that NRBF2-KO mice carrying 5XFAD hemizygous allele contained enhanced levels of insoluble $A \beta_{42}$ in the hippocampus compared to controls (Additional file 2: Figure S5D), further supporting that $N R B F 2$ deficiency accelerates the aggregation of insoluble $A \beta_{42}$ in the hippocampus.

\section{AAV transduction of NRBF2 into the dorsal hippocampus rescues autophagy and memory impairments of NRBF2- $K O$ and reduces $\beta$-amyloid load in SXFAD mice}

To test the specific function of hippocampal NRBF2 in maintaining memory integrity, we reinstated $N R B F 2$ expression in the hippocampal areas of NRBF2-KO mice by injecting recombinant adeno-associated viruses (rAAV) carrying either mCherry (AAV9-CMV-mCherry) or NRBF2mCherry (AAV9-CMV-NRBF2-mCherry) into the dorsal hippocampus (dHip) of 2-3 months old WT and NRBF2-
$K O$ mice. We then performed behavioral and biochemical analyses of these injected mice at 21-30 days post-injection. Through assessment of OLT and CFC tasks, we found that NRBF2-mCherry-injected KO mice showed greater discrimination and improved freezing behaviors when compared to mCherry-injected $\mathrm{KO}$ mice; and no differences was detected between mCherry-injected and NRBF2-mCherry injected WT mice (Fig. 4a-b). The above results demonstrate that the memory deficits in NRBF2-KO mice is caused by NRBF2 loss of function specifically in the dorsal hippocampus and can be reversed by reintroduction of NRBF2 expression. Further, our data suggests that the memory deficit of NRBF2-KO mice is unlikely caused by developmental effect or neurodegeneration. Indeed, we have not detected any signs of apoptosis in NRBF2-KO mouse hippocampus (Additional file 2: Figure S8A-B). Next, we examined autophagy status and found comparable levels of p62 or LC3-II proteins between NRBF2-mCherry-injected WT and KO mice, whereas p62 or LC3-II levels remained different between mCherryinjected WT and KO mice (Fig. 4c-e), suggesting a recovery

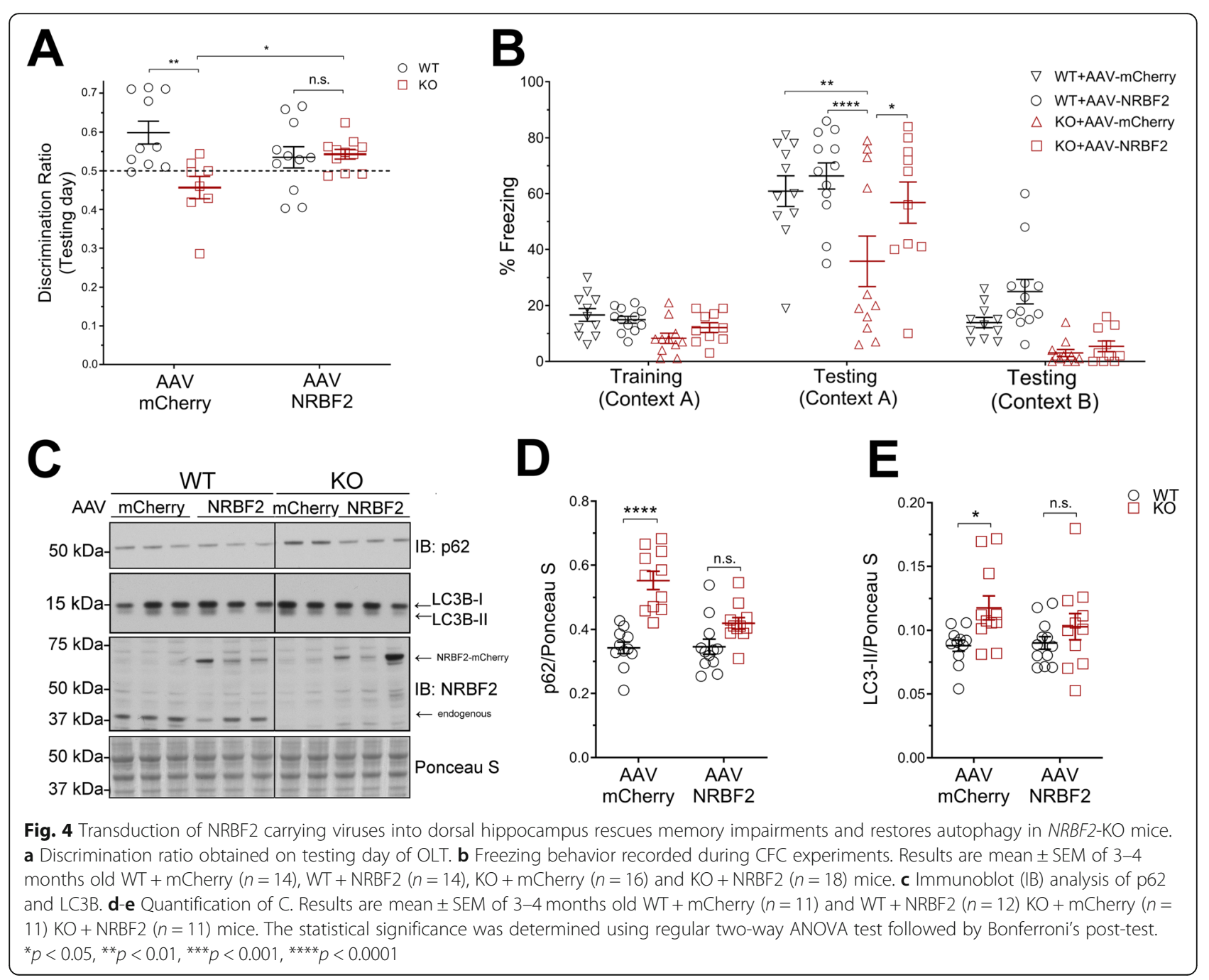


of autophagy in NRBF2-mCherry-injected KO mice. Moreover, ULK1-FIP200 interaction was improved in NRBF2mCherry-injected $\mathrm{KO}$ mice when compared to mCherryinjected KO mice (Additional file 2: Figure S2E-F).

Finally, we injected rAAV carrying NRBF2 into dHip of 5XFAD mice and tested their cognitive functions before and at 30- and 60-days post-injection (dpi). To do so we chose to use a spontaneous alternation task (SAT) since it is non-invasive and easily repeatable when compared to OLT and CFC tasks. We found that the SAT performance of NRBF2-mCherry-injected 5XFAD mice was improved when compared to that of mCherryinjected 5XFAD mice, while no change was observed between NRBF2-mCherry- and mCherry-injected WT mice (Fig. 5a). Of note, the total numbers of entries showed no significant differences between the groups (Fig. 5b). Importantly, while evaluating $\beta$-amyloid load in the injected 5XFAD brains, we observed a reduction of area coverage and the counts of particles as well as a trend decrease of the particles average size, of $A \beta$ staining in NRBF2-mCherry-injected mice at $60 \mathrm{dpi}$, when compared to mCherry-injected littermate controls, despite lower expression of NRBF2-mCherry than mCherry (Fig. 5c-d), suggesting that overexpression of NRBF2 decreases $\beta$-amyloid level in the hippocampus. Taken together, our data also suggest that increasing NRBF2 expression is neuroprotective as evidenced by lowering $\beta$-amyloid load and improving memory function in $\mathrm{AD}$ model.

\section{Discussion}

Several studies have attempted to characterize the changes of autophagy genes in AD brains. However, the results lack an agreement on the exact nature of the change in autophagy. By leveraging the transcriptomic dataset of a large $\mathrm{AD}$ cohort, our analysis reveals altered expression of specific

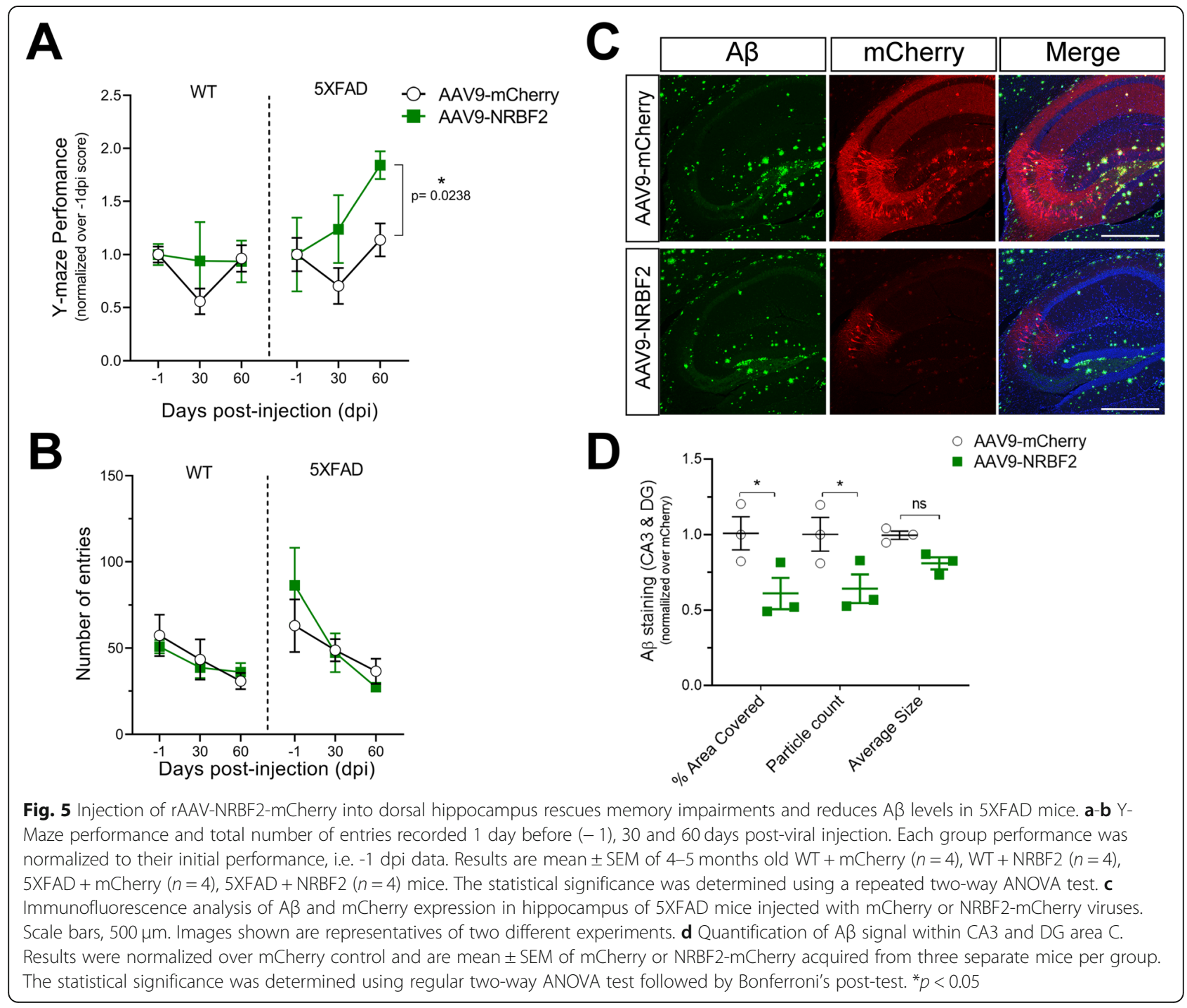


functional groups of autophagy genes in the PHG of $\mathrm{AD}$ patients. Our data shows that downregulation of various autophagy kinase complex components, e.g. BECN1-PIK 3C3, ULK1/2-ATG13-FIP200, and NRBF2, is prominent and coincides with the disease progression (CDR). Indeed, dysregulation of Beclin 1-PIK3C3 and ULK1 have already been reported in AD brains [10, 11, 13, 14, 48]. However, the significance of NRBF2 or its cellular functions in learning and memory has never been demonstrated.

Our study is the first to demonstrate that loss of NRBF2 and NRBF2-associated protein complex integrities promote memory impairments in young animals. Our findings of reduced expression of NRBF2 (along with other ATGs) in AD brains and characterization of NRBF2-KO mice support the role of impaired NRBF2-associated function in promoting memory dysfunctions and $\mathrm{AD}$ risk. Specifically, our study demonstrates that NRBF2-KO mice develop memory deficits through multiple cognition assays, i.e. working memory (RAM), reference memory (CFC) and recognition memory (OLT), while displaying minor change in anxiety-related behavior based on OF, LD and EPM studies. Thus, our data may suggest selective vulnerability of hippocampal regions responsible for memory function caused by deletion of NRBF2. Interestingly, these cognitive domains are known to be impaired in different $\mathrm{AD}$ mouse models and are recognized to model the preclinical behavioral changes observed in AD [49]. Our work therefore provide insight into how autophagy related processes, mediated by NRBF2, could potentially modulate pathogenic pathways in AD.

Furthermore, we showed that depletion of NRBF2 alters ULK1-FIP200 complex, in addition to Beclin 1PIK3C3 complex as we previously reported [22]. Reestablishing NRBF2 expression by viral transduction into dorsal hippocampus of $\mathrm{KO}$ mice rescues memory impairment, autophagy flux, ULK1-FIP200 interaction, thus supporting that memory deficits are unlikely caused by developmental effect or neurodegeneration. Therefore, the lack of NRBF2-related functions in the hippocampus primarily accounts for the memory impairment in the mutant mice. Our work shows an impairment of LTP while observing no change in basal synaptic transmission in the hippocampus of NRBF2-KO mice. However, the precise mechanism that contributes to LTP disruption remains to be clarified. One could suspect that a modification in AMPA receptors (AMPAR) trafficking is causing the LTP impairment or cognitive deficits in the mutant mice. In fact, BECN1-PIK3C3 and ULK1/2 complexes have been shown to promote endocytosis and ERto-Golgi trafficking respectively $[50,51]$. Therefore, dysregulation of the functions of these kinases beyond autophagy in the hippocampus of NRBF2-KO mice could disrupt the AMPAR trafficking and explain the LTP inhibition. Nevertheless, deeper mechanistic analysis is required to precisely define the molecular components contributing to the LTP impairment observed in NRBF2-KO mice.

\section{Conclusions}

In summary, our findings identify progressive decline in the expression of NRBF2 and NRBF2-associated autophagy complex in specific brain regions of $\mathrm{AD}$ patients, which correlates with clinical dementia progression. Our investigation reveals the impact of dysfunctional NRBF2related pathways in promoting $A \beta$ accumulation and memory deficits in experimental animal models. Our study also provides evidence that restoration or modulation of NRBF2 and perhaps its associated kinase complexes activities may represent a new therapeutic strategy for improving memory impairment related to AD.

\section{Supplementary information}

Supplementary information accompanies this paper at https://doi.org/10. 1186/s13024-019-0342-4.

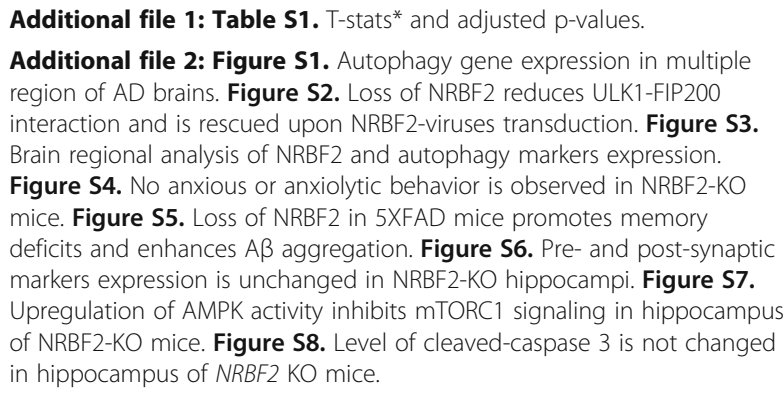

\section{Abbreviations}

AAV: Adeno-associated virus; AD: Alzheimer's Disease; AMPK: AMP-activated protein kinase; ATG: Autophagy-related; ATG13: Autophagy-related protein 13; $A \beta$ : amyloid- $\beta$; BECN1: Beclin 1; CFC: Contextual fear conditioning; ELISA: Enzyme-linked immunosorbent assay; FIP200: FAK family kinaseinteracting protein of 200 kDa; KO: Knockout; LC3: Microtubule-associated proteins 1A/1B light chain 3; LC3-II: LC3-phosphatidylethanolamine conjugate; LTP: Long-Term Potentiation; mTOR: Mammalian Target of Rapamycin; NRBF2: Nuclear Receptor Binding Factor 2; OLT: Object location task; p62/SQSTM1: Sequestosome-1; PIK3C3: Class III PI3-kinase; pTau: Hyperphosphorylated-tau; RAM: Radial-arm maze; SAT: Spontaneous alternation task; ULK1: Unc-51 Like Autophagy Activating Kinase 1; WT: Wild type

\section{Acknowledgements}

We thank members of the Yue, Lu, Sweet, Blitzer and Bozdagi-Gunal labs for technical assistance.

\section{Authors' contributions}

J-HL initiated the project. ES and OB-G performed and analyzed the electrophysiological experiments. QW executed the bio-informatics analysis. $J\lrcorner J$ and $Y Z$ help to score the videos recorded during the OLT task. C-ZC and $X-X Z$ performed and analyzed the experiments with aged mice. IC executed IHC experiments with 5XFAD mice injected with AAV viruses. VL designed, executed, and analyzed all the remaining experiments. $V L$ and $Z Y$ wrote the manuscript. OB-G, J-HL, QW, VL and ZY reviewed and edited the manuscript. All authors read and approved the final manuscript. 


\section{Funding}

This work was supported by NIH/NINDS R01-NS060123 (Z.Y.), NIH/NIMH R01MH103455 (O.B-G.), 2U01AG046170-06 (B.Z.), YS2017YFGH000899, FDCT-024/ 2017/AMJ, FDCT-022/2015/A1 (J-H.L), and CIHR postdoctoral fellowship MFE146812 (V.L.).

\section{Availability of data and materials}

The datasets supporting the conclusions of this article are included within the supplementary information available at Molecular Neurodegeneration website.

\section{Ethics approval}

All animal studies were conducted in compliance with the IACUC committee of Icahn School of Medicine at Mount Sinai.

\section{Consent for publication}

All authors read and approved the final manuscript.

\section{Competing interests}

The authors declare that they have no competing interests.

\section{Author details}

${ }^{1}$ Department of Neurology, The Friedman Brain Institute, Icahn School of Medicine at Mount Sinai, New York, NY 10029, USA. ${ }^{2}$ Department of Genetics and Genomic Sciences, Icahn School of Medicine at Mount Sinai, New York NY 10029, USA. ${ }^{3}$ Departments of Psychiatry and Pharmacological Sciences, Icahn School of Medicine at Mount Sinai, New York, NY 10029, USA. ${ }^{4}$ Present Address: Department of Biology, West Chester University, West Chester, PA 19383, USA. ${ }^{5}$ State Key Laboratory of Quality Research in Chinese Medicine, Institute of Chinese Medical Sciences, University of Macau, Taipa, Macau SAR, China. ${ }^{6}$ Department of Neuroscience, Icahn School of Medicine at Mount Sinai, New York, NY 10029, USA. ${ }^{7}$ Present Address: Department of Psychiatry, Rutgers New Jersey Medical School, Newark, NJ 07103, USA.

\section{Received: 6 July 2019 Accepted: 31 October 2019}

\section{Published online: 27 November 2019}

\section{References}

1. Mawuenyega KG, Sigurdson W, Ovod V, Munsell L, Kasten T, Morris JC, Yarasheski KE, Bateman RJ. Decreased clearance of CNS beta-amyloid in Alzheimer's disease. Science. 2010;330:1774.

2. Wang J, Gu BJ, Masters CL, Wang YJ. A systemic view of Alzheimer disease insights from amyloid-beta metabolism beyond the brain. Nat Rev Neurol. 2017:13:612-23.

3. Masters CL, Bateman R, Blennow K, Rowe CC, Sperling RA, Cummings JL. Alzheimer's disease. Nat Rev Dis Primers. 2015:1:15056.

4. Grune T, Jung T, Merker K, Davies KJ. Decreased proteolysis caused by protein aggregates, inclusion bodies, plaques, lipofuscin, ceroid, and 'aggresomes' during oxidative stress, aging, and disease. Int J Biochem Cell Biol. 2004;36:2519-30.

5. Vellai T. Autophagy genes and ageing. Cell Death Differ. 2009;16:94-102.

6. Morawe T, Hiebel C, Kern A, Behl C. Protein homeostasis, aging and Alzheimer's disease. Mol Neurobiol. 2012:46:41-54.

7. Menzies FM, Fleming A, Caricasole A, Bento CF, Andrews SP, Ashkenazi A, Fullgrabe J, Jackson A, Jimenez Sanchez M, Karabiyik C, et al. Autophagy and Neurodegeneration: pathogenic mechanisms and therapeutic opportunities. Neuron. 2017;93:1015-34.

8. Uddin MS, Stachowiak A, Mamun AA, Tzvetkov NT, Takeda S, Atanasov AG, Bergantin LB, Abdel-Daim MM, Stankiewicz AM. Autophagy and Alzheimer's disease: from molecular mechanisms to therapeutic implications. Front Aging Neurosci. 2018;10:04

9. Nixon RA, Wegiel J, Kumar A, Yu WH, Peterhoff C, Cataldo A, Cuervo AM Extensive involvement of autophagy in Alzheimer disease: an immunoelectron microscopy study. J Neuropathol Exp Neurol. 2005:64:113-22.

10. Li X, Alafuzoff I, Soininen H, Winblad B, Pei JJ. Levels of mTOR and its downstream targets $4 \mathrm{E}-\mathrm{BP} 1$, eEF2, and eEF2 kinase in relationships with tau in Alzheimer's disease brain. FEBS J. 2005;272:4211-20.

11. Pickford F, Masliah E, Britschgi M, Lucin K, Narasimhan R, Jaeger PA, Small S, Spencer B, Rockenstein E, Levine B, Wyss-Coray T. The autophagy-related protein beclin 1 shows reduced expression in early Alzheimer disease and regulates amyloid beta accumulation in mice. J Clin Invest. 2008;118:2190-9.
12. Lipinski MM, Zheng B, Lu T, Yan Z, Py BF, Ng A, Xavier RJ, Li C, Yankner BA, Scherzer CR, Yuan J. Genome-wide analysis reveals mechanisms modulating autophagy in normal brain aging and in Alzheimer's disease. Proc Natl Acad Sci U S A. 2010;107:14164-9.

13. Ma T, Chen Y, Vingtdeux V, Zhao H, Viollet B, Marambaud P, Klann E. Inhibition of AMP-activated protein kinase signaling alleviates impairments in hippocampal synaptic plasticity induced by amyloid beta. J Neurosci. 2014;34:12230-8.

14. Mairet-Coello G, Courchet J, Pieraut S, Courchet V, Maximov A, Polleux F. The CAMKK2-AMPK kinase pathway mediates the synaptotoxic effects of Abeta oligomers through tau phosphorylation. Neuron. 2013;78:94-108.

15. Chen Y, Zhou K, Wang R, Liu Y, Kwak YD, Ma T, Thompson RC, Zhao $Y$, Smith L, Gasparini L, et al. Antidiabetic drug metformin (GlucophageR) increases biogenesis of Alzheimer's amyloid peptides via up-regulating BACE1 transcription. Proc Natl Acad Sci U S A. 2009; 106:3907-12.

16. Bordi M, Berg MJ, Mohan PS, Peterhoff CM, Alldred MJ, Che S, Ginsberg SD, Nixon RA. Autophagy flux in CA1 neurons of Alzheimer hippocampus: increased induction overburdens failing lysosomes to propel neuritic dystrophy. Autophagy. 2016;12:2467-83.

17. Behrends C, Sowa ME, Gygi SP, Harper JW. Network organization of the human autophagy system. Nature. 2010;466:68-76.

18. Lamb CA, Yoshimori T, Tooze SA. The autophagosome: origins unknown, biogenesis complex. Nat Rev Mol Cell Biol. 2013;14:759-74.

19. Homma K, Suzuki K, Sugawara H. The autophagy database: an all-inclusive information resource on autophagy that provides nourishment for research. Nucleic Acids Res. 2011;39:D986-90.

20. Wang M, Beckmann ND, Roussos P, Wang E, Zhou X, Wang Q, Ming C, Neff R, Ma W, Fullard JF, et al. The Mount Sinai cohort of large-scale genomic, transcriptomic and proteomic data in Alzheimer's disease. Sci Data. 2018;5:180185.

21. Ritchie ME, Phipson B, Wu D, Hu Y, Law CW, Shi W, Smyth GK. limma powers differential expression analyses for RNA-sequencing and microarray studies. Nucleic Acids Res. 2015:43:e47.

22. Lu J, He L, Behrends C, Araki M, Araki K, Jun Wang Q, Catanzaro JM, Friedman SL, Zong WX, Fiel MI, et al. NRBF2 regulates autophagy and prevents liver injury by modulating Atg14L-linked phosphatidylinositol-3 kinase III activity. Nat Commun. 2014:5:3920.

23. Brai E, Alina Raio N, Alberi L. Notch1 hallmarks fibrillary depositions in sporadic Alzheimer's disease. Acta Neuropathol Commun. 2016:4:64.

24. Gassmann M, Grenacher B, Rohde B, Vogel J. Quantifying Western blots: pitfalls of densitometry. Electrophoresis. 2009;30:1845-55.

25. Miedel CJ, Patton JM, Miedel AN, Miedel ES, Levenson JM. Assessment of Spontaneous Alternation, Novel Object Recognition and Limb Clasping in Transgenic Mouse Models of Amyloid- $\beta$ and Tau Neuropathology. J Vis Exp. 2017;123:e55523. https://doi.org/10.3791/55523.

26. Mitchell AC, Javidfar B, Bicks LK, Neve R, Garbett K, Lander SS, Mirnics K, Morishita $H$, Wood MA, Jiang $Y$, et al. Longitudinal assessment of neuronal 3D genomes in mouse prefrontal cortex. Nat Commun. 2016;7:12743.

27. Bozdagi O, Sakurai T, Papapetrou D, Wang X, Dickstein DL, Takahashi N, Kajiwara Y, Yang M, Katz AM, Scattoni ML, et al. Haploinsufficiency of the autism-associated Shank3 gene leads to deficits in synaptic function, social interaction, and social communication. Mol Autism. 2010;1:15.

28. Liang WS, Dunckley T, Beach TG, Grover A, Mastroeni D, Walker DG, Caselli RJ, Kukull WA, McKeel D, Morris JC, et al. Gene expression profiles in anatomically and functionally distinct regions of the normal aged human brain. Physiol Genomics. 2007;28:311-22.

29. Yang C, Cai CZ, Song JX, Tan JQ, Durairajan SSK, lyaswamy A, Wu MY, Chen LL, Yue Z, Li M, Lu JH. NRBF2 is involved in the autophagic degradation process of APP-CTFs in Alzheimer disease models. Autophagy. 2017;13:2028-40.

30. Ma X, Zhang S, He L, Rong Y, Brier LW, Sun Q, Liu R, Fan W, Chen S, Yue Z, et al. MTORC1-mediated NRBF2 phosphorylation functions as a switch for the class III Ptdlns3K and autophagy. Autophagy. 2017;13:592-607.

31. Ohashi Y, Soler N, Garcia Ortegon M, Zhang L, Kirsten ML, Perisic O, Masson GR, Burke JE, Jakobi AJ, Apostolakis AA, et al. Characterization of Atg38 and NRBF2, a fifth subunit of the autophagic Vps34/PIK3C3 complex. Autophagy. 2016:12:2129-44.

32. Cao Y, Wang Y, Abi Saab WF, Yang F, Pessin JE, Backer JM. NRBF2 regulates macroautophagy as a component of Vps34 complex I. Biochem J. 2014;461:315-22. 
33. Zhong Y, Morris DH, Jin L, Patel MS, Karunakaran SK, Fu YJ, Matuszak EA, Weiss HL, Chait BT, Wang QJ. Nrbf2 protein suppresses autophagy by modulating Atg14L protein-containing Beclin 1-Vps34 complex architecture and reducing intracellular phosphatidylinositol-3 phosphate levels. J Biol Chem. 2014;289:26021-37.

34. Young LN, Cho K, Lawrence R, Zoncu R, Hurley JH. Dynamics and architecture of the NRBF2-containing phosphatidylinositol 3-kinase complex I of autophagy. Proc Natl Acad Sci U S A. 2016;113:8224-9.

35. Yoshii SR, Mizushima N. Monitoring and measuring autophagy. Int J Mol Sci. 2017;18(9):1865,

36. Bannerman DM, Sprengel R, Sanderson DJ, McHugh SB, Rawlins JN, Monyer $\mathrm{H}$, Seeburg PH. Hippocampal synaptic plasticity, spatial memory and anxiety. Nat Rev Neurosci. 2014;15:181-92.

37. Broadbent NJ, Squire LR, Clark RE. Spatial memory, recognition memory, and the hippocampus. Proc Natl Acad Sci U S A. 2004;101:14515-20.

38. Kim J, Kundu M, Viollet B, Guan KL. AMPK and mTOR regulate autophagy through direct phosphorylation of Ulk1. Nat Cell Biol. 2011;13:132-41.

39. Potter WB, O'Riordan KJ, Barnett D, Osting SM, Wagoner M, Burger C, Roopra A. Metabolic regulation of neuronal plasticity by the energy sensor AMPK. PLoS One. 2010;5:e8996.

40. Bavley CC, Rice RC, Fischer DK, Fakira AK, Byrne M, Kosovsky M, Rizzo BK, Del Prete D, Alaedini A, Moron JA, et al. Rescue of Learning and Memory Deficits in the human Nonsyndromic intellectual disability Cereblon Knockout mouse model by targeting the AMP-activated protein kinase-mTORC1 translational pathway. J Neurosci. 2018;38:2780-95.

41. Gwinn DM, Shackelford DB, Egan DF, Mihaylova MM, Mery A, Vasquez DS, Turk BE, Shaw RJ. AMPK phosphorylation of raptor mediates a metabolic checkpoint. Mol Cell. 2008;30:214-26.

42. Peterson RT, Beal PA, Comb MJ, Schreiber SL. FKBP12-rapamycin-associated protein (FRAP) autophosphorylates at serine 2481 under translationally repressive conditions. J Biol Chem. 2000;275:7416-23.

43. Gingras AC, Gygi SP, Raught B, Polakiewicz RD, Abraham RT, Hoekstra MF, Aebersold R, Sonenberg N. Regulation of 4E-BP1 phosphorylation: a novel two-step mechanism. Genes Dev. 1999;13:1422-37.

44. Stoica L, Zhu PJ, Huang W, Zhou H, Kozma SC, Costa-Mattioli M. Selective pharmacogenetic inhibition of mammalian target of Rapamycin complex I (mTORC1) blocks long-term synaptic plasticity and memory storage. Proc Natl Acad Sci U S A. 2011;108:3791-6.

45. Ma T, Hoeffer CA, Capetillo-Zarate E, Yu F, Wong H, Lin MT, Gouras GK Dysregulation of the mTOR pathway mediates impairment of synaptic plasticity in a mouse model of Alzheimer's disease. PloS one. 2010;5(9): e12845

46. Banko JL, Poulin F, Hou L, DeMaria CT, Sonenberg N, Klann E. The translation repressor 4E-BP2 is critical for elF4F complex formation, synaptic plasticity, and memory in the hippocampus. J Neurosci. 2005;25:9581-90.

47. Oakley H, Cole SL, Logan S, Maus E, Shao P, Craft J, Guillozet-Bongaarts A, Ohno M, Disterhoft J, Van Eldik L, et al. Intraneuronal beta-amyloid aggregates, neurodegeneration, and neuron loss in transgenic mice with five familial Alzheimer's disease mutations: potential factors in amyloid plaque formation. J Neurosci. 2006:26:10129-40.

48. Cordero JG, Garcia-Escudero R, Avila J, Gargini R, Garcia-Escudero V. Benefit of Oleuropein Aglycone for Alzheimer's disease by promoting autophagy. Oxidative Med Cell Longev. 2018;2018:5010741.

49. Webster SJ, Bachstetter AD, Nelson PT, Schmitt FA, Van Eldik LJ. Using mice to model Alzheimer's dementia: an overview of the clinical disease and the preclinical behavioral changes in 10 mouse models. Front Genet. 2014;5:88.

50. Joo JH, Wang B, Frankel E, Ge L, Xu L, lyengar R, Li-Harms X, Wright C, Shaw $\mathrm{TI}$, Lindsten T, et al. The noncanonical role of ULK/ATG1 in ER-to-Golgi trafficking is essential for cellular homeostasis. Mol Cell. 2016:62:491-506.

51. Bechtel W, Helmstadter M, Balica J, Hartleben B, Schell C, Huber TB. The class III phosphatidylinositol 3-kinase PIK3C3NPS34 regulates endocytosis and autophagosome-autolysosome formation in podocytes. Autophagy. 2013;9:1097-9.

\section{Publisher's Note}

Springer Nature remains neutral with regard to jurisdictional claims in published maps and institutional affiliations.

\section{Ready to submit your research? Choose BMC and benefit from}

- fast, convenient online submission

- thorough peer review by experienced researchers in your field

- rapid publication on acceptance

- support for research data, including large and complex data types

- gold Open Access which fosters wider collaboration and increased citations

- maximum visibility for your research: over $100 \mathrm{M}$ website views per year

At BMC, research is always in progress.

Learn more biomedcentral.com/submissions 